Tropical Journal of Pharmaceutical Research September 2014; 13 (9): 1415-1419

ISSN: $1596-5996$ (print); 1596-9827 (electronic)

(c) Pharmacotherapy Group, Faculty of Pharmacy, University of Benin, Benin City, 300001 Nigeria.

All rights reserved.

Available online at http://www.tjpr.org

Original Research Article

http://dx.doi.org/10.4314/tjpr.v13i9.6

\title{
Anti-inflammatory Effects of (-)-Epicatechin in Lipopolysaccharide-Stimulated Raw 264.7 Macrophages
}

\author{
Hai Wang ${ }^{1 *}$ and Zhi-Ran $\mathrm{CaO}^{2}$ \\ ${ }^{1}$ Medical Department, The Second Central Hospital of Baoding City, Hebei 072750, ${ }^{2}$ Department of Immunology, School of \\ Basic Medicine, Hebei University Health Science Center, Hebei 071000, China \\ *For correspondence: Email: wanghai201311@163.com; Tel: +86-312-3966325
}

Received: 29 April 2014

Revised accepted: 15 August 2014

\begin{abstract}
Purpose: To investigate the protective effects of (-)-epicatechin on lipopolysaccharide (LPS)-induced inflammation in Raw 264.7 murine macrophages and the possible underlying mechanisms.

Methods: The effects of epicatechin on LPS-stimulated production of inflammatory mediators in Raw 264.7 cells were evaluated by enzyme-linked immunosorbent assay.

Results: Epicatechin in doses of 5, 25 and $50 \mu \mathrm{M}$ remarkably $(p<0.05)$ inhibited the production of proinflammatory mediators including nitric oxide (NO) and prostaglandin E2 (PGE $)$, as well as the production of pro-inflammatory cytokines including tumor necrosis factor (TNF)-alpha and interleukin (IL)-6 in LPS-induced Raw 264.7 macrophages.

Conclusion: The results suggest that epicatechin can inhibit inflammatory response and may be a potential therapeutic candidate for the treatment of chronic inflammatory diseases.
\end{abstract}

Key words: Inflammation, Epicatechin, Cytokines, Nitric oxide, Prostaglandin E2, Macrophages

Tropical Journal of Pharmaceutical Research is indexed by Science Citation Index (SciSearch), Scopus, International Pharmaceutical Abstract, Chemical Abstracts, Embase, Index Copernicus, EBSCO, African Index Medicus, JournalSeek, Journal Citation Reports/Science Edition, Directory of Open Access Journals (DOAJ), African Journal Online, Bioline International, Open-J-Gate and Pharmacy Abstracts

\section{INTRODUCTION}

Inflammation is one of the body's self-defense mechanisms which is characterized by redness, pain, swelling and a sensation of heat. The inflammatory responses play an important role in host survival although it can also lead to chronic inflammatory diseases such as asthma [1], cancer [2], rheumatoid arthritis [3], Crohn's disease [4] and ulcerative colitis (UC) [5]. Inflammation can be initiated by a microbial pathogen such as lipopolysaccharide (LPS). LPS is a prototypical endotoxin, which can directly activate macrophages [6]. The production of inflammatory cytokines such as interleukin-6 (IL6 ), tumor necrosis factor-alpha (TNF-alpha), and other inflammatory mediators including nitric oxide (NO) and prostaglandin E2 $\left(\mathrm{PGE}_{2}\right)$ is increased during the processes of inflammation in activated macrophages [7].

Natural flavonoids are a group of polyphenolic compounds that are present in tea, grapes and other plants as well as in wine and cocoa [8-10]. Many studies show that consumption of flavonoid-rich foods exhibited regression of inflammatory diseases [11]. These beneficial effects of flavonoids might be partially attributed to their anti-oxidative capacity. Epicatechin is a natural phenolic compound found widely in plants, and possesses anti-oxidative, anti-cancer and other biological activities [12,13].

Therefore, the objective of the present study was to evaluate the anti-inflammatory activities of epicatechin on Raw 264.7 mouse macrophages. 


\section{EXPERIMENTAL}

\section{Chemicals and reagents}

Dimethyl sulfoxide (DMSO), lipopolysaccharide (LPS, Escherichia coli 055:B5) and 3-(4,5dimethylthiazol-2-yl)-2,5-diphenyltetrazolium bromide (MTT) were purchased from Sigma Chemical Co. (St. Louis, MO). (-)-Epicatechin was purchased from the National Institute for the Control of Pharmaceutical and Biological Products (Jilin, China). Dulbecco's modified Eagle's medium (DMEM), fetal bovine serum (FBS), penicillin and streptomycin were from Invitrogen Gibco BRL (Grand Island, NY). Mouse TNF-alpha and IL-6 enzyme-linked immunosorbent assay (ELISA) kits were purchased from Biolegend (San Diego, CA). All other chemicals were used of reagent grade.

\section{Cell culture}

Raw 264.7 mouse macrophages cell line was obtained from Cell Storehouse of Chinese Academy of Science (Shanghai, China) and cultured in Dulbecco's modified Eagle's medium (DMEM) supplemented with $10 \%$ fetal bovine serum and $1 \%$ of penicillin and streptomycin. The cells were incubated in a humidified incubator with $5 \% \mathrm{CO}_{2}$ atmosphere at $37^{\circ} \mathrm{C}$.

\section{Cell viability assay}

MTT assay was used for evaluating the effects of (-)-epicatechin on the cell viability. In brief, the cells were seeded into 96-well plates at a density of $1 \times 10^{5}$ cells $/ \mathrm{ml}$. Cells were treated with different concentrations $(0-50 \mu \mathrm{M})$ of (-)epicatechin for $1 \mathrm{~h}$, followed by stimulation with LPS $(1 \mu \mathrm{g} / \mathrm{ml})$ for $24 \mathrm{~h}$. Then, $30 \mu \mathrm{l}$ of MTT (5 $\mathrm{mg} / \mathrm{ml}$ ) were added into each well, and incubated for another $4 \mathrm{~h}$. After replacing the culture supernatant with $100 \mu \mathrm{l}$ of DMSO, the optical density of plates was read at a wavelength of $570 \mathrm{~nm}$ using a microplate reader (TECAN, Austria).

\section{$\mathrm{NO}$ and $\mathrm{PGE}_{2}$ production}

Mouse macrophages Raw 264.7 cells were pretreated with various concentrations $(5,25$ and 50 $\mu \mathrm{M})$ of epicatechin for $24 \mathrm{~h}$ before stimulating with LPS $(1 \mu \mathrm{g} / \mathrm{ml})$. After $18 \mathrm{~h}$ incubation, the levels of nitrate and $P E_{2}$ in the culture supernatant were calculated and determined by Griess and PGE $\mathrm{E}_{2}$ ELISA kits, respectively.

\section{Cytokine assay}

The cell-free supernatants were collected after treatment with (-)-epicatechin and LPS for $24 \mathrm{~h}$, and measured for the pro-inflammatory cytokines (TNF-alpha and IL-6) production by commercial ELISA kits (R \& D Systems), following the manufacturer's protocol.

\section{Statistical analysis}

Data are expressed as the mean \pm standard deviation (SD). Statistical analyses and significance, as measured by one-way analysis of variance (ANOVA), were performed using GraphPad PRISM software version 5.0 (GraphPad Software, USA). In all comparisons, $p$ $<0.05$ was considered statistically significant.

\section{RESULTS}

\section{Effect of (-)-epicatechin on cells viability in Raw 264.7 macrophages}

The results of MTT assays show that there were no significant changes in cell viabilities by epicatechin treatment with tested concentrations (Fig 1). Therefore, we used non-toxic concentrations $(5,25$ and $50 \mu \mathrm{M})$ for the entire experiment.

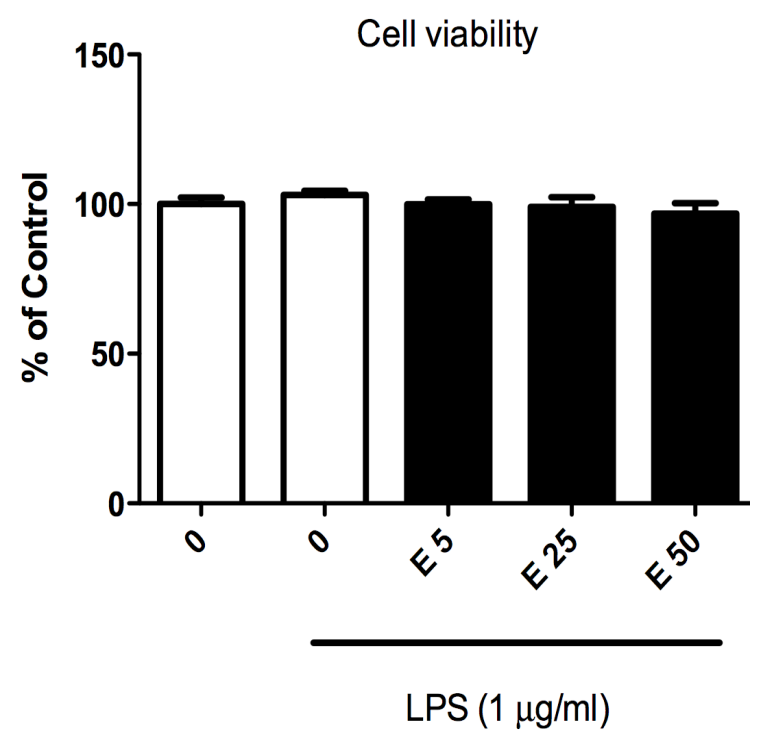

Fig 1: Effects of (-)-epicatechin on cell viability in LPStreated Raw 264.7 mouse macrophage cells. Raw 264.7 cells were cultured with (-)-epicatechin in the presence of LPS $(1 \mu \mathrm{g} / \mathrm{ml})$ for $24 \mathrm{~h}$. Cell viability was tested by MTT reduction assays. Values are presented as mean \pm standard deviation (SD) of three independent experiments 
Effects of (-)-epicatechin on the production of pro-inflammatory cytokines in LPS-stimulated macrophages

Treatment with LPS alone in Raw 264.7 cells resulted in a significant increase of TNF-alpha and IL-6 production compared with the control group (Fig 2). However, treatment with epicatechin $(5,25$ and $50 \mu \mathrm{M})$ remarkably inhibited LPS-induced TNF-alpha and IL-6 production in a dose-dependent manner (Fig 2).
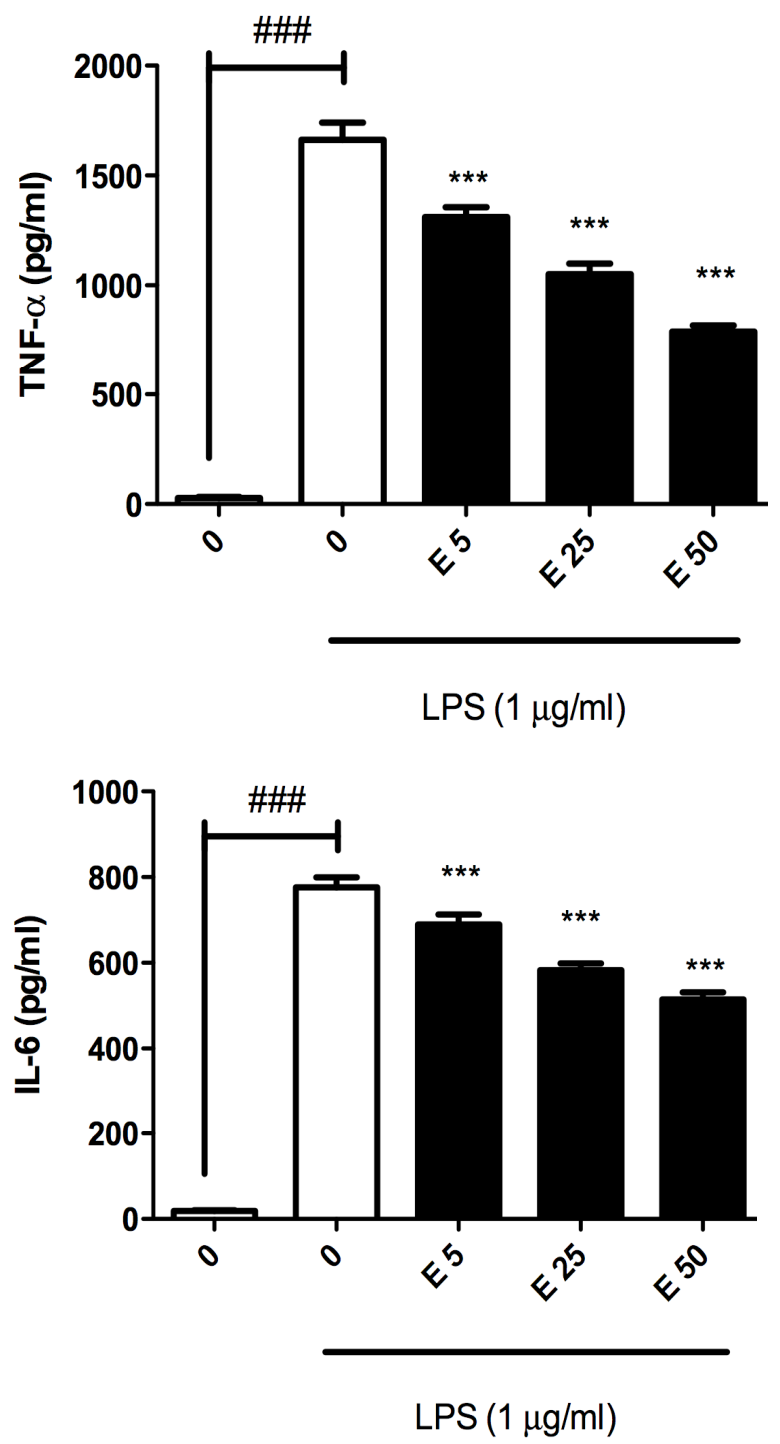

Fig 2: Effect of (-)-epicatechin on the production of TNF-alpha and IL-6 in LPS-stimulated Raw 264.7 cells. The cells were treated with LPS alone or LPS plus various concentrations $(5,25$, and $50 \mu \mathrm{M})$ of $(-)$ epicatechin for $24 \mathrm{~h}$. Values represent mean \pm SD of three independent experiments. The differences between mean values were assessed by student's $t$ test. ${ }^{\# \# \# ~} p<0.001$ indicates significant differences from the unstimulated control group; ${ }^{\star \star \star} p<0.001$ versus the LPS alone treatment control

\section{Effects of (-)-epicatechin on $\mathrm{NO}$ and $\mathrm{PGE}_{2}$ production in LPS-stimulated macrophages}

NO production was significantly inhibited by (-)epicatechin treatment compared to LPS alonetreatment. Besides, the inhibitory levels of (-)epicatechin on $\mathrm{NO}$ and $\mathrm{PGE}_{2}$ production also showed a dose-dependent pattern (Fig 3).
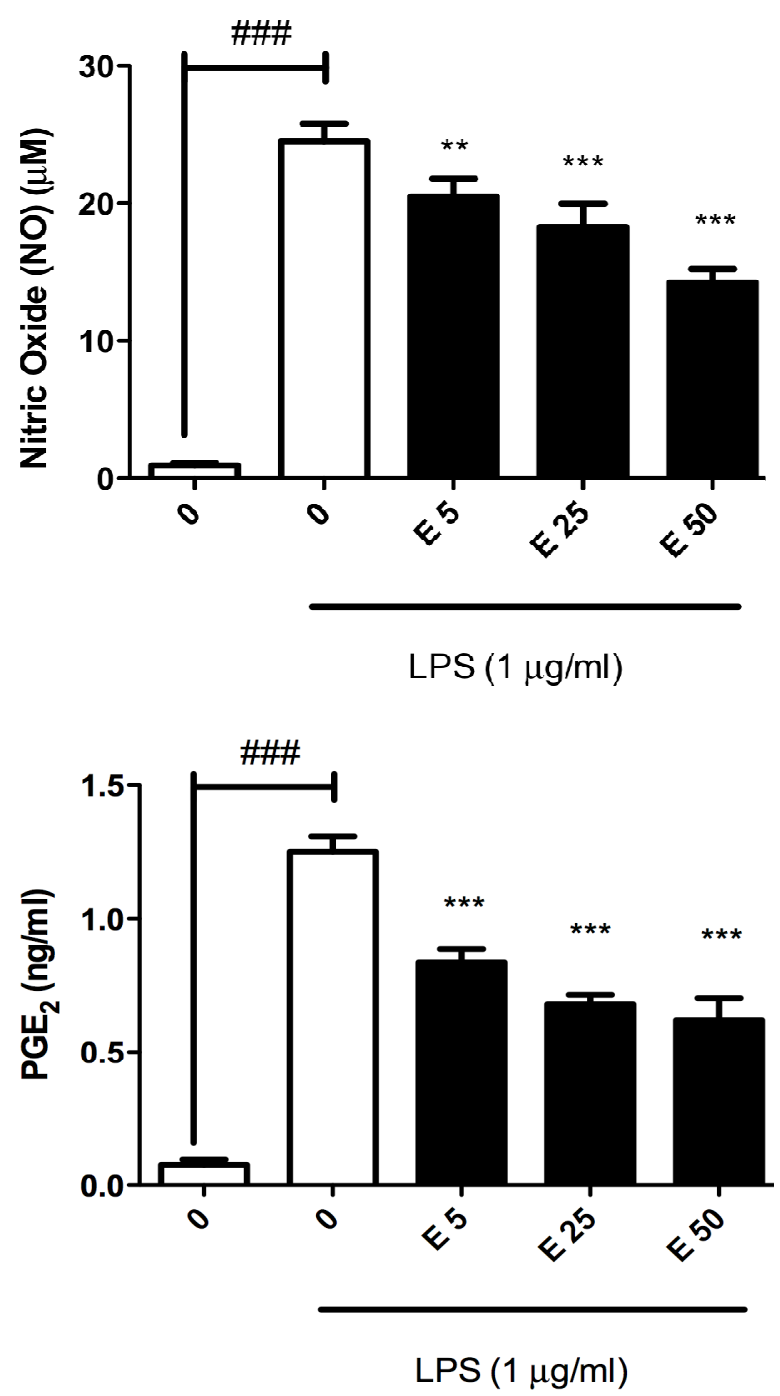

Fig 3: Effects of (-)-epicatechin on $\mathrm{NO}$ and $\mathrm{PGE}_{2}$ production in LPS-stimulated Raw 264.7 macrophages. Cells were incubated with LPS (1 $\mathrm{ug} / \mathrm{ml}$ ) for $18 \mathrm{~h}$ in the absence or presence of $(-)$ epicatechin. Cells were treated with (-)-epicatechin $1 \mathrm{~h}$ prior to addition of LPS. Nitrite and $\mathrm{PGE}_{2}$ production in the medium was determined using the Griess reagent and $\mathrm{PGE}_{2}$ EIA Kit. Data show the mean \pm SD of three independent experiments. The differences between mean values were assessed by student's $t$-test. ${ }^{\# \# \#} p<$ 0.001 indicates significant differences from the unstimulated control group; ${ }^{* * *} p<0.001$ versus the LPS alone treatment control 


\section{DISCUSSION}

In the present study, we investigated the effects of (-)-epicatechin on the production of proinflammatory mediators in LPS-stimulated Raw 264.7 mouse macrophages. The results demonstrate that (-)-epicatechin effectively inhibited LPS-induced release of TNF-alpha, IL$6, \mathrm{NO}$, and $\mathrm{PGE}_{2}$ production in LPS-stimulated macrophages, suggesting that (-)-epicatechin possesses potent anti-inflammatory effects.

Chronic inflammation is one of the major inducers of various diseases. Many proinflammatory cytokines such as TNF- $\alpha$ and IL-6, as well as other inflammatory mediators including $\mathrm{NO}$ and $\mathrm{PGE}_{2}$ are produced during the inflammation process [2]. These mediators drive the recruitment and initiation of macrophages and other immune cells to complete a full cycle of inflammation and interfere with metabolic functions [14]. These inflammatory mediators are risk factors that can stimulate angiogenesis and therefore promote tumor growth in the inflammatory lesion [15].

TNF-alpha and IL-6 are pro-inflammatory cytokines produced by various immune cells including macrophages, monocytes and lymphocytes in response to inflammation and infection [16]. Growing evidence demonstrate that TNF-alpha and IL-6 played a central role in the inflammatory process during cancer development, leading a new direction of therapeutics, the pro-inflammatory cytokines blocking agents [15]. $\mathrm{NO}$ and $\mathrm{PGE}_{2}$ also work as pro-inflammatory mediators that are produced by inducible nitric oxide synthase (iNOS) and cyclooxygenase (COX-2) respectively, which are involved in the innate response in activating macrophages [17].

In our present study, (-)-epicatechin showed that it could significantly suppress the releases of TNF-alpha and IL-6, and the production of NO and $\mathrm{PGE}_{2}$ in LPS-stimulated macrophages in a dose-dependant manner. The potencies of the inhibitory activities of (-)-epicatechin on Raw 264.7 mouse macrophages are comparable to those of epigallocatechin gallate (EGCG), another anti-inflammatory compound isolated from green tea [12].

\section{CONCLUSION}

The results obtained here demonstrate that (-)epicatechin is able to inhibit various pro- inflammatory mediators in antigen-activated macrophages, and also shows a capacity to attenuate cytokine-mediated inflammation. These results also suggest that (-)-epicatechincontaining diets have beneficial effects in preventing various inflammation-related diseases including cancers and IBD.

\section{REFERENCES}

1. Dos SG, Kutuzov MA, Ridge KM: The inflammasome in lung diseases. Am J Physiol Lung Cell Mol Physiol (2012) 303(8):L627-633.

2. Elinav $E$, Nowarski $R$, Thaiss $C A, H u$ B, Jin $C$, Flavell RA: Inflammation-induced cancer: Crosstalk between tumours, immune cells and microorganisms. Nat Rev Cancer (2013) 13(11):759-771.

3. Pablos JL, Canete JD: Immunopathology of rheumatoid arthritis. Curr Top Med Chem (2013) 13(6):705-711.

4. Scharl M, Rogler G: Inflammatory bowel disease: Dysfunction of autophagy? Dig Dis (2012) 30 Suppl 3(12-19.

5. Ali RA, Egan LJ: How to manage the risk of colorectal cancer in ulcerative colitis. Curr Drug Targets (2011) 12(10):1424-1432.

6. Rossol M, Heine H, Meusch U, Quandt D, Klein C, Sweet MJ, Hauschildt S: Lps-induced cytokine production in human monocytes and macrophages. Crit Rev Immunol (2011) 31(5):379-446.

7. Lawrence $T$, Willoughby DA, Gilroy DW: Antiinflammatory lipid mediators and insights into the resolution of inflammation. Nat Rev Immunol (2002) 2(10):787-795.

8. Ly BT, Chi HT, Yamagishi M, Kano Y, Hara Y, Nakano K, Sato $Y$, Watanabe $T$ : Inhibition of flt3 expression by green tea catechins in flt3 mutated-aml cells. PLoS One (2013) 8(6):e66378.

9. Scola G, Conte D, Spada PW, Dani $C$, Vanderlinde $R$, Funchal C, Salvador M: Flavan-3-ol compounds from wine wastes with in vitro and in vivo antioxidant activity. Nutrients (2010) 2(10):1048-1059.

10. Fraga CG, Litterio MC, Prince PD, Calabro V, Piotrkowski $B$, Galleano M: Cocoa flavanols: Effects on vascular nitric oxide and blood pressure. J Clin Biochem Nutr (2011) 48(1):63-67.

11. Mennen LI, Sapinho D, de Bree A, Arnault N, Bertrais S, Galan $P$, Hercberg $S$ : Consumption of foods rich in flavonoids is related to a decreased cardiovascular risk in apparently healthy french women. I Nutr (2004) 134(4):923-926.

12. Zhong $Y$, Chiou YS, Pan MH, Shahidi F: Antiinflammatory activity of lipophilic epigallocatechin gallate (egcg) derivatives in Ips-stimulated murine macrophages. Food Chem (2012) 134(2):742-748.

13. Zhou J, Gong ZL, Zhang K, Ding YP: Advance in anticancer studies on catechins and their derivatives. Zhongguo Zhong Yao Za Zhi (2012) 37(17):25102518.

Trop J Pharm Res, September 2014; 13(9): 1418 


\section{Wang \& Cao}

14. Medzhitov R: Origin and physiological roles of inflammation. Nature (2008) 454(7203):428-435.

15. Cook J, Hagemann T: Tumour-associated macrophages and cancer. Curr Opin Pharmacol (2013) 13(4):595601.

16. Laveti D, Kumar M, Hemalatha R, Sistla R, Naidu VG, Talla $V$, Verma $V$, Kaur $N$, Nagpal R: Anti- inflammatory treatments for chronic diseases: $A$ review. Inflamm Allergy Drug Targets (2013) 12(5):349-361.

17. Alexander C, Rietschel ET: Bacterial lipopolysaccharides and innate immunity. J Endotoxin Res (2001) 7(3):167-202. 